\title{
Integrating interpreters into CAMHS: useful tips for effective co-working
}

\author{
By Dr. Jessica K Edwards
}

Vicci Ackroyd and Barry Wright have put together a useful set of principals by which British Sign Language (BSL) interpreters, and child and adolescent mental health services (CAMHS) can effectively co-work with each other. Published in the Journal of Community Healthcare, Ackroyd and Wright explain that BSL interpreters form a crucial component of the multi-disciplinary therapeutic team. Indeed, a CAMHS audit in 20121 found that BSL interpreters predominantly work side-by-side with clinicians and contribute to team meetings (Figure $\mathbf{1}$ ). Ackroyd et al. highlight how essential it is that interpreters work flexibly to accommodate various communication styles (taking into account cultural and linguistic differences) and explain any communication difficulties to the clinician. In addition, both the interpreter and the clinician should reassure children and their families about patient confidentiality, and allow adequate time after a session to debrief. Going forward, Ackroyd and Wright highlight the importance of interpretation being of a high standard and that interpreters are respectful of the independence and autonomy of the deaf person and have experience of working within CAMHS.

\section{Referring to:}

Ackroyd, V. \& Wright, B. (2018), Working with British Sign Language (BSL) interpreters: lessons from child and adolescent mental health services in the U.K. J. Commun. Healthc. 11: 195-204. doi: $10.1080 / 17538068.2018 .1492218$.

\section{References:}

${ }^{1}$ Knight A. Northern National Deaf CAMHS: Team Interpreter Audit, Results and Recommendations. York: National Deaf CAMHS (Northern Arm); March 2012.

Figure 1: Percentage of time team interpreters spent by activity Reproduced with permission from Ackroyd, V. \& Wright, B. (2018), Working with British Sign Language (BSL) interpreters: lessons from child and adolescent mental health services in the U.K. J. Commun. Healthc. 11: 195-204. doi: 10.1080/17538068.2018.1492218.

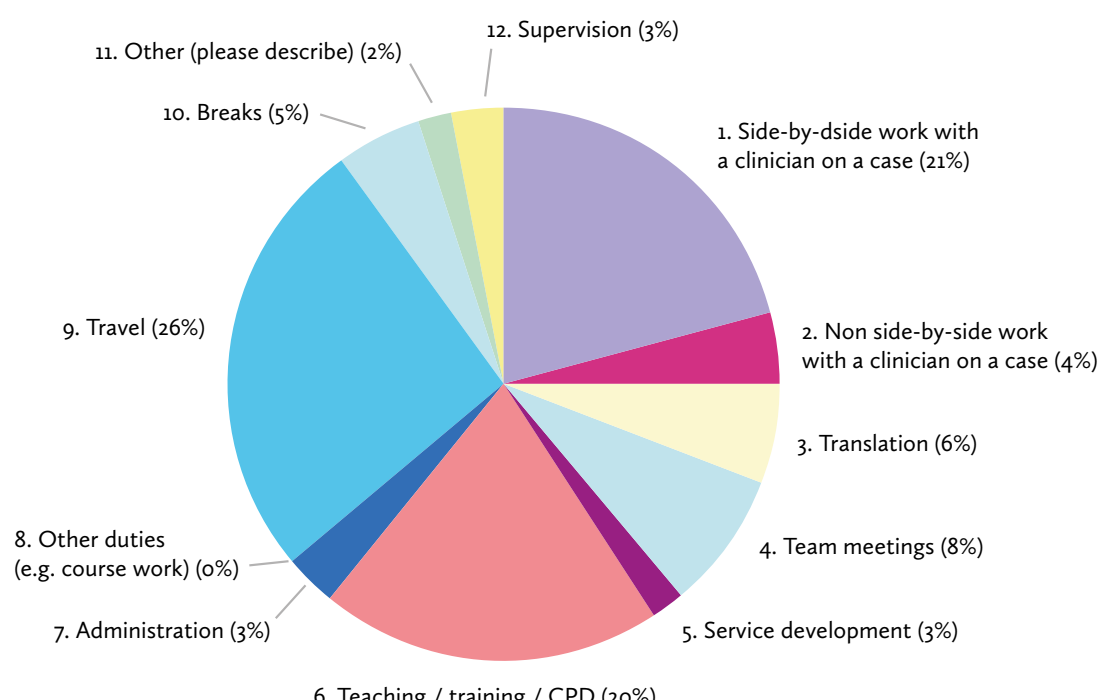

6. Teaching / training / CPD (20\%)

Figure 1. Percentage of time team interpreters spent by activity (Time 2). 